\title{
Proceso monitorio: ¿qué hacer cuando no se logra notificar personalmente al demandado?
}

Ariel Rincón-Almeyda*

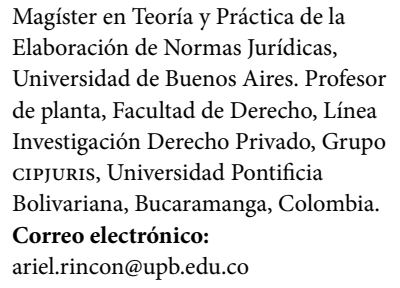

Magíster en Teoría y Práctica de la Elaboración de Normas Jurídicas, Universidad de Buenos Aires. Profesor de planta, Facultad de Derecho, Línea Investigación Derecho Privado, Grupo CIPJURIs, Universidad Pontificia Bolivariana, Bucaramanga, Colombia. Correo electrónico:

ariel.rincon@upb.edu.co

Recibido: 31 agosto del 2016

Aprobado: 28 de noviembre del 2016

Cómo citar este artículo: Ariel RincónAlmeyda. Proceso monitorio: ¿qué hacer cuando no se logra notificar personalmente al demandado? DIXI 25. Enero 2017.

Págs. 49-58. doi: http://dx.doi.org/10.16925/ di.v19i25.1820

\section{Resumen}

Tema y alcance: el proceso monitorio ha sido una de las instituciones jurídicas que más ha generado comentarios y despertado inquietudes en la comunidad jurídica colombiana desde que se propuso como institución a incorporarse en el Código General del Proceso. Dicha institución procesal tiene sus orígenes en la Edad Media y se desarrolla, históricamente, incorporándose en los diferentes sistemas procesales. Características: entre sus características es posible identificar la celeridad, la posibilidad de sentencia sin controversia y su carácter estrictamente patrimonial. Hallazgos: sin embargo, la incorporación de dicha institución jurídica acarrea el problema de su inutilización, pues ante la imposibilidad de notificar al demandado, la salida jurídica que tiene el demandante es retirar la demanda e iniciar otro tipo de actuación jurídica. Conclusiones: el artículo que se presenta tiene como finalidad demostrar que las limitaciones impuestas a la forma de notificación en el proceso monitorio conllevan a la denegación de justicia, así como que el ciudadano termine no utilizando el proceso monitorio, sino las formas tradicionales a fin de constituir un título ejecutivo.

Palabras clave: Código General del Proceso, legística, notificación personal, proceso monitorio. 


\title{
Order for payment procedure: What to do when the defendant cannot be personally served?
}

\begin{abstract}
Theme and scope: the order for payment procedure has been one of the legal institutions that has generated the most comments and raised concerns in the Colombian legal community since it was proposed as an institution to be incorporated into the General Code of Procedure. This procedural institution dates back to the Middle Ages and has been historically introduced in different procedural systems. Characteristics: some of the characteristics identified are speed, the possibility of a final judgment, and its strictly pecuniary nature. Findings: however, the incorporation of this legal institution entails the problem of its disuse, because, when the defendant cannot be served, the legal option that the plaintiff has is to withdraw the claim and initiate another type of legal action. Conclusions: the purpose of this article is to prove that the limitations imposed on the form of summons in the order for payment procedure lead to the denial of justice while the citizen ends up not using the order for payment procedure, but traditional methods in order to obtain a writ of execution.
\end{abstract}

Keywords: General Code of Procedure, legistics, summons, order for payment procedure.

\section{Procedimento monitório: o que fazer quando não se consegue notificar pessoalmente ao requerido?}

\section{Resumo}

Tema e alcance: o procedimento monitório tem sido uma das instituições jurídicas que mais tem gerado comentários e despertado dúvidas na comunidade jurídica colombiana desde que foi proposto como instituição a ser incorporada no Código Geral do Processo. Essa instituição processual tem sua origem na Idade Média e desenvolve-se, historicamente, incorporando-se nos diferentes sistemas processuais. Características: entre suas características, é possível identificar a celeridade, a possibilidade de sentença sem controvérsia e seu caráter estritamente patrimonial. Achados: contudo, a incorporação dessa instituição jurídica acarreta o problema de sua inutilização, pois, diante da impossibilidade de notificar ao requerido, a saída jurídica que tem o requerente é retirar a ação e iniciar outro tipo de litígio jurídico. Conclusões: este artigo tem o objetivo de demonstrar que as limitações impostas à forma de notificação no procedimento monitório implicam a denegação de justiça bem como a inutilização do procedimento monitório por parte do cidadão, mas sim utilize as formas tradicionais a fim de constituir um título executivo.

Palavras-chave: Código Geral do Processo, legística, notificação pessoal, procedimento monitório. 


\section{INTRODUCCIÓN}

Uno de los inconvenientes permanentes de las democracias modernas estriba en la dificultad para acercar el producto del proceso de elaboración normativa a los recipiendarios de la misma, es decir, hacer posible el conocimiento de la norma por los destinatarios.

En principio, el destinatario de toda norma es el ciudadano, quien debe adecuar su conducta a lo que la norma dispone, lo cual ya implica un problema de comunicación e incorporación cultural de la norma. La realidad sociojurídica de nuestro país conduce a determinar que el ciudadano básicamente no conoce la norma, motivo por el cual el derecho requiere de la famosa cláusula de cierre "el desconocimiento de la norma no es excusa". Con esta cláusula se cierra la posibilidad interpretativa del desconocimiento del derecho.

Ahora, el problema se agudiza si verificamos que quienes tienen la obligación en el sistema jurídico de aplicar la norma, la desconocen. Corroborar esta situación implicaría por lo menos dos conclusiones $a$ priori: 1. Las normas no son discutidas antes de ser promulgadas en el seno de los recipiendarios de las normas; y 2. No existe un mecanismo eficaz de divulgación de la norma aprobada en el Congreso.

Estos problemas, que no son más que problemas de legística, empiezan a nacer con el actual Código General del Proceso (Ley 1564 de 2012), pues la Corte Constitucional, mediante la Sentencia C-726-2014, declaró la constitucionalidad del proceso monitorio y estableció un primer límite a la notificación al demandado del auto de requerimiento de pago, la cual se debe hacer de forma personal y sin posibilidad de otro medio de notificación.

El propósito del presente artículo consiste en determinar la dificultad que acarrea la implementación del proceso monitorio, dadas las restricciones planteadas en el Código General del Proceso y por la Corte Constitucional para adelantar la notificación al demandado.

El Código General del Proceso contempla que dentro de un proceso monitorio queda prohibido el emplazamiento y el curador ad litem. Por su parte, la Corte Constitucional indicó que en el proceso monitorio también queda prohibida la notificación por aviso. Con lo anterior, la solución procesal que tiene el demandante, en caso de no poder notificar personalmente al demandado, es retirar la demanda e iniciar la constitución del título ejecutivo por las formas tradicionales, esto es, citar a conciliación o citar a interrogatorio de parte como prueba extraprocesal, o bien iniciar proceso verbal sumario.

\section{TEMA Y ALCANCES}

\section{A. Antecedentes históricos del proceso monitorio}

El concepto básico de la palabra monitorio consiste en la "monición, amonestación o advertencia que el Papa, los obispos y prelados dirigían a los fieles en general para la averiguación de ciertos hechos o para señalarles normas de conducta, principalmente en relación con circunstancias de actualidad". ${ }^{1}$ De esta fórmula o convención social se ha derivado su uso convencional en dos sentidos: 1. En tanto adjetivo sirve para avisar o amonestar; ${ }^{2}$ y 2 . En tanto persona sirve para identificar al individuo que avisa o amonesta. ${ }^{3}$

Ahora bien, el uso de esta palabra también se ha puesto a disposición del derecho para significar, tanto un adjetivo, como una personificación del mismo. El primer sentido, de acuerdo con Calvinho - entre otros-, al sostener que el objeto del monitorio es "crear un verdadero título ejecutivo - en realidad ejecutorio: que valga per se-, cuyo inicio ante la autoridad correspondiente desembocara en una orden de ejecución directa - denominada Sentencia Monitoria-". En el segundo sentido se ha expresado Calamandrei, quien considera el monitorio como aquel "que obtiene o pretende por medio unilateral una actuación jurisdiccional un título ejecutivo para una ulterior efectividad".

De estas dos acepciones, hemos llegado a la institucionalización generalizada en el derecho procesal de entender el monitorio como una clase en específica de proceso. Para llegar a esta institución, alguna parte de la academia busca sus raíces en el derecho romano, ${ }^{6}$ a partir del Corpus Iuris Canonici, estableciendo que dicho cuerpo normativo contemplaba la posibilidad que tiene el juez de eliminar ciertos formalismos y eliminar actuaciones dilatorias.

\footnotetext{
1. Véase Real Academia Española. Diccionario. Real Academia EsPañola. Disponible en http://lema.rae.es/drae/?val=monitorio 2. Con este uso podemos formar la frase: "El profesor envió un monitorio a María para que se ponga al día con sus tareas".

3. Con este uso podemos formar la frase: "El profesor es un monitorio".

4. Véase Gustavo Calvinho. Debido proceso y procedimiento MOnitorio. Pág. 4. Disponible en http://www.petruzzosc.com.ar/ articulos_y_publicaciones/Debido_Proceso_y_procedimiento_ monitorio.pdf

5. Véase Piero Calamandrei. El Procedimiento Monitorio. Librería El Foro. (2007). Pág. 31.

6. Véase Ximena Andrea Lanos Torres y Claudia Patricia Torres Montaño. La Implementación del Proceso Monitorio en eL Ordenamiento Procesal Civil Colombiano. Pág. 12. Disponible en http://repository.unimilitar.edu.co/bitstream/10654/10900/1/LanosTorresXimenaAndrea2014.pdf
} 
Esta visión parece un tanto errada, en el sentido que la norma romana simplemente preveía una facultad al juez, pero en ningún momento establecía una clase de proceso similar al monitorio, tal como se conoce hoy en día.

Sin embargo, el referente histórico de mayor aceptación académica consiste en ubicar el origen del proceso monitorio en las ciudades italianas del siglo XIII, con la figura procesal del mandatum de solvendo cum clausula iustificativa. ${ }^{7}$ Este mandato consistía en una alternativa al juicio ordinario a efectos de poder crear un título ejecutivo, pues cabe recordar que en esta época el comercio marítimo adquiere relevancia y el comerciante requiere de mecanismos eficaces y ágiles que permitan el curso del comercio.

Las razones o justificaciones de la necesidad de este tipo de procesos durante el siglo xIII las expresa el profesor Chiovenda, al sostener que "las nuevas formas de actividades comerciales, del naciente grupo de la burguesía de las ciudades-Estado, les resulte más rápido un mecanismo más eficiente y menos formalista para la resolución de las deudas civiles y mercantiles".

Un tercer momento de desarrollo histórico del proceso monitorio lo encontramos durante el siglo $\mathrm{xv}$ en la tradición germánica. Los tratadistas alemanes fueron influidos por las corrientes italianas del siglo XIII, y durante el $\mathrm{xV}$ introdujeron el mandatum cum clausula, con la variante según la cual antes que el juez ordene el mandatum, requiere por parte de este una investigación preliminar. ${ }^{9}$

\section{B. Algunas referencias del proceso monitorio en el derecho comparado contemporáneo}

\section{España}

El proceso monitorio en España fue introducido al sistema jurídico mediante la Ley de Enjuiciamiento Civil. ${ }^{10}$ Esta norma reglamenta el proceso monitorio

\footnotetext{
7. Véase Gustavo Calvinho, supra, nota 4; véase también Piero Calamandrei, supra, nota 5 .

8. Véase José Alejandro Gómez Orozco. InTroducción AL Proceso monitorio Colombiano: Constitucionalidad Y Oralidad del Derecho Civil. Librería Jurídica Sánchez R. Ltda. (2014). Pág. 57.

9. Véase Antonio Segni. El procedimiento intimatorio en Italia. ReVISTA DE DERECHO PRIVAdo 168. 1927. Págs. 307-318; véase también Felipe Varcalcel Prieto. El Proceso Monitorio. Disponible en http://dspace.sheol.uniovi.es/dspace/bitstream/10651/28743/3/ TFMValcarcel\%20Pri eto,\%20Felipe.pdf

10. Véase Ley 1/2000. De enjuiciamiento civil de enero 7 del 2000. (Enero 8 del 2000). вов 7 (Esp.).
}

entre los artículos 812 y 818 . Los mencionados artículos establecen o consolidan lo que la doctrina ha denominado "proceso monitorio documental", esto es, "la exigencia de un título documental, normalmente firmado por el deudor, que prima facie incorpore la existencia de una deuda". ${ }^{11}$

Por otra parte, el artículo 815 de la Ley de Enjuiciamiento Civil establece que la forma de notificación será personal, mediante el procedimiento de la citación contenido en el artículo 161 de la misma norma. Con todo, si no es posible la notificación personal, el artículo establece la posibilidad de la notificación mediante "comunicación edictal", la cual está reglamentada en el artículo 164 de la Ley de Enjuiciamiento Civil y consiste en publicar un edicto en el "tablón de anuncios del juzgado", y se incorporará en el Boletín Oficial.

Otra de las características básicas del proceso monitorio español radica en la limitación de la cuantía. En principio, la norma contemplaba que este proceso era viable para cuantías no superiores a cinco millones de pesetas, es decir, aproximadamente 30000 euros. Sin embargo, ante la proliferación de juicios monitorios, se expidió la Ley 13 de 2009 que incrementó la posibilidad de juicio monitorio para cuantías que no excedan los 250000 euros. $^{12}$

\section{Unión Europea}

Dado el alto impacto que tuvo el proceso monitorio en Estados que lo venían aplicando históricamente, como es caso de Italia y Alemania, ${ }^{13}$ la Unión Europea, a través del Parlamento Europeo, decidió crear la Institución del Proceso Monitorio para asuntos Transfronterizos. Dicha decisión fue asumida mediante el Reglamento 1896 de $2006 .{ }^{14}$

El Reglamento Europeo por el cual se crea el Proceso Monitorio Europeo, en su artículo 4, señala que "se establece el proceso monitorio europeo para el cobro de créditos pecuniarios, de importe determinado, vencidos y exigibles en la fecha en que se presenta la petición de requerimiento europeo de pago". ${ }^{15} \mathrm{La}$ anterior definición nos conduce a clasificar este proceso

\footnotetext{
11. Véase Joan PicóI. Junoy. El Proceso Monitorio una Visión Europea y Española de la Tutela Rápida del Crédito. Pág. 5. Disponible en http://www.icdp.org.co/revista/articulos/37/JoanPicoIJunoy.pdf 12. Id. Pág. 1

13. Véase José Alejandro Gómez Orozco, supra, nota 9. Pág. 62. 14. Véase Reglamento (CE) N. 1896/2006 [Parlamento Europeo y del Consejo]. Por el que se establece un proceso monitorio europeo. Diciembre 12 del 2006.

15. Id. Art. 4
} 
monitorio dentro de los denominados "procesos monitorios puros", es decir, aquellos procesos en los cuales "no es preciso aportar junto a la demanda ninguna base documental". ${ }^{16}$

Por su parte, la notificación del requerimiento europeo de pago está reglamentada entre los artículos 13 y 15 del Reglamento 1896 de 2006. Dicha referencia normativa establece que se notificará de conformidad con el derecho nacional del Estado donde deba hacer la notificación, teniendo como referencia la notificación personal con acuse de recibo, la notificación personal acreditada por un documento, la notificación por correo acreditada mediante acuse de recibo y la notificación por medios electrónicos como telecopia o correo electrónico. La mencionada norma también contempla la posibilidad de notificar el requerimiento europeo de pago sin acuse de recibo y mediante representante. ${ }^{17}$

\section{Uruguay}

Uruguay se considera uno de los primeros países latinoamericanos en implementar el proceso monitorio. En este sentido, Couture considera:

Uruguay conoce el proceso dotado de estructura monitoria desde 1878, año que entró en vigencia el viejo código de procedimiento civil, cuerpo normativo en el cual se consagró para los juicios de entrega de la cosa (cierta y determinada) y de entrega efectiva de la herencia. Posteriormente, dicho procedimiento se extendió al juicio de desalojo (ley 8.153 del año 1927) $y$ al juicio ejecutivo (ley 13.355 de 1965). ${ }^{18}$

El antecedente inmediato de la implementación del proceso monitorio al actual Código General del Proceso lo constituye el Código Procesal Civil Modelo para Iberoamérica, realizado a instancias del Instituto Iberoamericano de Derecho Procesal. ${ }^{19}$ Dicho antecedente se consolidó en Uruguay mediante la expedición del Código General del Proceso de 1988, ${ }^{20}$ actualmente modificado mediante la Ley 19.090 de $2013 .{ }^{21}$ En el

16. Véase Joan PicóI. Junoy, supra, nota 11. Pág. 5.

17. Véase Reglamento (CE) N. ${ }^{\circ} 1896 / 2006$, supra, nota 14. Arts. 13, 14 y 15.

18. Véase Eduardo J. Couture. Los Otros Procesos Monitorios en el Código General del Proceso Uruguayo, xxxv Congreso Colombiano De Derecho Procesal. (2014). Pág. 790

19. Cf. Santiago Pereira Campos. Los Proceso Civiles por Audiencias en Uruguay. 20 Años de aplicación exitosa del Código Procesal Civil Modelo para Iberoamérica. Revista InTERNACIONAL DE Estudios sobre Derecho Procesal y Arbitraje. 2. 2009. Pág. 7.

20. Cf. Ley 15.982/1988. (Octubre 18 de 1988). Do 22.743 (Uruguay).

21. Cf. Ley 19.090/2013. (Junio 14 de 2013). Do 28.743 (Uruguay).
Código General del Proceso de 1988 ya se establecía el proceso monitorio, "en el cual se pronuncia al inicio una sentencia definitiva que adquirirá la calidad de cosa juzgada condicionada a la no oposición de excepciones".22

El Código General del Proceso uruguayo reglamenta el Proceso de Estructura Monitoria entre los artículos 351 y 370 del Código General del Proceso. Dicha norma contempla una estructura mixta en la posibilidad de acceder al monitorio. En este sentido, establece que para "promover la demanda, se requerirá documento auténtico o autenticado notarial o judicialmente en la etapa preliminar respectiva". ${ }^{23}$ Con todo, este requisito procesal se podrá obviar si el contrato es susceptible de probarse mediante testigos. ${ }^{24}$ Esta connotación hace pensar en una clasificación mixta del proceso monitorio, en el sentido que permite la posibilidad pura y la documental.

Respecto a la notificación, la norma procesal uruguaya establece, en su artículo 355 del Código General del Proceso, que se debe hacer mediante el mecanismo del emplazamiento, consagrado en el artículo 123 de la misma norma. Dicha referencia normativa establece que "el emplazamiento consiste en la convocatoria al demandado para que comparezca a estar a derecho dentro del plazo que corresponda, haciéndole saber, en la forma prevista por la ley, la interposición de la demanda o el estado del proceso, con apercibimiento de que, en caso de no comparecer, se seguirá el proceso con las consecuencias que la ley determine, según los casos".

\section{Procedimiento legislativo en Colombia del Código General del Proceso}

El Código General del Proceso ${ }^{26}$ es la culminación de un proceso académico liderado por diferentes especialistas en la materia, pero especialmente orientado y coordinado por el Instituto Colombiano de Derecho Procesal. Este instituto, "emprendió en el año 2003 la necesaria tarea de elaborar un nuevo código de

\footnotetext{
22. Véase Ángel Landoni Sosa. Luces y Sombras den la Reforma del Código General del Proceso Uruguayo. La Ley 1909 Vigente del 14 de Agosto de 2013. xxxv Congreso Colombiano De Derecho Procesal. 2014. Pág. 762.

23. Cf. Ley 15.982/1988, supra, nota 20. Art. 352.1.

24. Id. Art. 352.2.

25. Id. Art. 123.1.

26. Véase Ley 1564 de 2012. Por medio de la cual se expide el Código General del Proceso y se dictan otras disposiciones. (Julio 12 del 2012). Do 48.489.
} 
procedimiento, con el propósito principal de mejorar el servicio de justicia". ${ }^{27}$

La finalidad de este nuevo estatuto procesal consistía básicamente en armonizar las normas procesales con la Constitución de 1991, la eficacia del derecho (esto es, la efectividad del derecho sustancial sobre el formal), la oralidad como garantía de inmediación y celeridad, el acceso a la justicia garantizado con un lenguaje más cercano al ciudadano, la unificación nacional mediante la reducción en el Código General del Proceso de procesos y materias, ${ }^{28}$ y la modernización en la administración de justicia a través de la posibilidad del uso de nuevas tecnologías. ${ }^{29}$

El proyecto de ley fue finalmente solicitado por el Ministerio del Interior y de Justicia en el 2010 al Instituto Colombiano de Derecho Procesal. Tarea esta que fue cumplida en febrero del 2011, para luego ser radicado ante el Congreso de la República en marzo del mismo año.

El proyecto de ley surtió los cuatro debates correspondientes, y fue aprobado en primer debate el 17 de mayo del 2011 por la Comisión Primera de la Cámara de Representantes. El segundo debate se surtió ante la plenaria de la Cámara de Representantes, y fue aprobado el 18 de octubre del 2011. El tercer debate se surtió ante la Comisión Primera del Senado, y fue aprobado el 11 de abril del 2012. Finalmente, el cuarto y último debate se surtió ante la plenaria del Senado el 30 de mayo del 2012. La norma fue sancionada por el presidente de la República el 12 de julio del 2012. ${ }^{30}$

La vigencia del Código General del Proceso fue determinada en el artículo 627, estableciendo, básicamente, un mecanismo de vigencia inmediata de algunas normas, y el código en su integralidad supeditado a que el Consejo Superior de la Judicatura disponga de la logística e infraestructura necesaria. En términos generales, el Consejo Superior de la Judicatura cuenta con un plazo de tres años, contados a partir del 1 de enero del 2014 para la implementación plena del código. Con todo, el mencionado referente normativo indica que a partir del primero de enero del 2017 la norma entrará en vigencia en todos los distritos judiciales del país. ${ }^{31}$

\footnotetext{
27. Cf. Ulises Canosa Suárez. Código General del Proceso. Instituto Colombiano de Derecho Procesal. (2012). Pág. 7.

28. La idea inicial era concebir un código que unificara procesos en materia civil, comercial, laboral y administrativo. Por diferentes razones esta pretensión no se cumplió y las materias de procedimiento laboral y administrativo están reguladas por sus propios estatutos procesales.

29. Cf. Ulises Canosa Suárez, supra, nota 27. Págs. 7-11.

30. Id. Págs. 12 y 13

31. Véase Ley 1564 de 2012, supra, nota 26. Pág. 627.
}

Entre las finalidades del nuevo estatuto procesal, como lo señalan Tapias Amalia et al., se encuentra, "la celeridad de todos los procesos judiciales con observancia de las garantías procesales, en aras de obtener una sentencia justa y pronta; para lo cual, trae consigo un número significativo de cambios y de novedosas instituciones". 32

\section{CARACTERÍSTICAS}

\section{A. El proceso monitorio en el Código General del Proceso}

El Código General del Proceso agrupó los procedimientos en cuatro clases: declarativos, ejecutivo, liquidación y jurisdicción voluntaria. Dentro de los procesos declarativos, estableció la subclasificación de procesos declarativos especiales, entre los cuales enmarcó el proceso monitorio. De esta forma, el proceso monitorio tiene la categoría de proceso declarativo, pues su finalidad es la configuración de un título ejecutivo.

El proceso monitorio quedó reglamentado entre los artículos 419 y 421 del Código General del Proceso. El artículo 419 establece: "Quien pretenda el pago de una obligación en dinero, de naturaleza contractual, determinada y exigible que sea de mínima cuantía, podrá promover proceso monitorio con sujeción a las disposiciones de este capítulo". ${ }^{33}$ Esta conceptualización de inmediato nos remite a la clasificación de proceso monitorio de naturaleza pura, es decir, no se requiere de una base documental a efectos de solicitar el trámite monitorio.

A su vez, la referencia normativa establece un límite en razón de la cuantía. Solo se podrán promover procesos monitorios cuya cuantía no excedan los 40 salarios mínimos legales mensuales vigentes, ${ }^{34}$ esto es, COP 29508,680 .

El artículo 419 del Código General del Proceso, a su vez consagra la naturaleza contractual de la obligación, con lo cual excluye cualquier otra fuente de las obligaciones. En este mismo sentido, el artículo 420, numeral 5 del Código General del Proceso, advierte que, como requisito de la demanda, se debe manifestar

\footnotetext{
32. Véase Amalia Tapias Tapias, Rafael Evelio Muñoz Sánchez y Lil Medina Ortiz. Algunas Vicisitudes del Proceso Monitorio en ColombiaUna Visión Desde la Academia. DIXI 18(24). 2016. Pág. 49-62. 33. Véase Ley 1564 de 2012, supra, nota 26. 34. Id. art. 25.
} 
que el pago de la suma de dinero no depende de una contraprestación a cargo del acreedor.

El artículo 421 del Código General del Proceso establece el procedimiento específicamente, el cual consiste en la expedición por parte del juez de un requerimiento de pago al deudor, el cual debe ser notificado personalmente. Frente a este requerimiento de pago, el deudor tiene varias opciones: 1. Pagar, con lo cual el proceso termina; 2. Notificarse personalmente y no proponer excepciones dentro de los diez días siguientes, caso en el cual se dictará sentencia que no admite recursos y hace tránsito a cosa juzgada, y se dará el trámite ejecutivo del artículo 306 del Código General del Proceso; 3. Notificarse personalmente y proponer excepciones dentro de los diez días siguientes, caso en el cual se deberá tramitar la audiencia contemplada en el artículo 392 del Código General del Proceso, la cual es la prevista para el proceso verbal sumario; 4. No notificarse personalmente, caso en el cual queda abierta la posibilidad interpretativa, bien sea para darle trámite a la notificación por aviso contemplada en los artículos 291 numeral 6 y 292 del Código General del Proceso, o bien para dar por terminado el proceso por imposibilidad de notificación personal, y tendrá el demandante que iniciar un proceso verbal sumario.

\section{Hallazgos}

Esta última posibilidad interpretativa (la de dar por terminado el proceso por imposibilidad de notificación personal) que se deriva de la Sentencia C-726/2014, es la que precisamente va en contravía de los principios mismos del Código General del Proceso, pues entre ellos la interpretación de la norma procesal indica que prima la efectividad de los derechos sustanciales. En este mismo sentido, dentro de los poderes del juez está el de salvaguardar el proceso a efectos de evitar dilaciones de justicia.

De igual forma, el artículo 421 del Código General del Proceso, en su inciso segundo establece:

El auto que contiene el requerimiento de pago no admite recursos y se notificará personalmente al deudor, con la advertencia de que si no paga o no justifica su renuncia, se dictará sentencia que tampoco admite recursos y constituye cosa juzgada, en la cual se le condenará al pago del monto reclamado, de los intereses causados y de los que se causen hasta la cancelación de la deuda. Si el deudor satisface la obli- gación en la firma señalada, se declarará terminado el proceso por pago. ${ }^{35}$

Este artículo del Código General del Proceso fue demandado por inconstitucional y la Corte Constitucional se pronunció mediante Sentencia C-726 de 2014. El argumento central del demandante, respecto a la notificación, consistía en determinar que:

El auto de requerimiento de pago es violatorio del debido proceso porque no admite recursos y al haber sido eliminados los actos procesales de intervención de terceros, el emplazamiento del demandado, el nombramiento de curador ad litem, las excepciones previas y la posibilidad de presentar demanda de reconvención, se limita el derecho de defensa del demandado, con lo cual el juez se pronuncia con efectos de cosa juzgada, sin haber oído al deudor frente a quien se constituye un título ejecutivo. ${ }^{36}$

Dicho argumento fue rebatido por la Corte Constitucional estableciendo que precisamente el legislador contempló la figura de la notificación personal a efectos de garantizar la defensa del demandado. En palabras textuales, la Corte estableció en el numeral 6.4 de la Sentencia C-726 de 2014:

En complemento de lo anterior, en este tipo de proceso especial, el requerimiento que hace el juez reviste una doble naturaleza. De una parte, constituye la notificación y a la vez, el requerimiento de pago, el cual debe ser notificado personalmente, sin que sea posible la notificación por aviso [cursivas añadidas]. El parágrafo del artículo 421 del Código General del Proceso de manera expresa prohíbe el emplazamiento del demandado, lo que comporta la garantía de la que dispone el deudor para actuar en el proceso y no permitir que se constituya un título de ejecución sin su conocimiento. ${ }^{37}$

Es evidente que esta interpretación de la Corte contraría lo expresado por la norma procesal, pues esta última, en el parágrafo del artículo 421 establece la prohibición específica de notificación por emplazamiento, pero nada prohíbe respecto a la notificación por aviso. El parágrafo del artículo 421 del Código General del Proceso establece:

\footnotetext{
35. Véase Ley 1564 de 2012, supra, nota 26. 36. Véase Corte Constitucional de Colombia. Sentencia C-726/2014. (MP Martha Sáchica; septiembre 21 del 2014). 37. Id.
} 
En este proceso no se admitirá intervención de terceros, excepciones previas, reconvención, el emplazamiento del demandado, ni el nombramiento de curador ad litem. Podrán practicarse las medidas cautelares previstas para los demás proceso declarativos. Dictada la sentencia a favor del acreedor, proceden las medidas cautelares propias de los proceso ejecutivos. ${ }^{38}$

Ahora bien, el inconveniente con la interpretación propuesta por la Corte Constitucional radica en la inoperancia del proceso monitorio, pues un ciudadano que ha sido demandado mediante proceso monitorio puede simplemente recibir la citación a presentación de notificación personal y hacer caso omiso de la misma. El demandante queda ante la imposibilidad de hacer comparecer al proceso al demandado y verá burlada su expectativa de una solución pronta a su conflicto.

El aviso es una forma de notificación contemplada en el Código General del Proceso en el artículo 292, y puede obrar como una forma subsidiaria de notificación cuando no se pueda hacer la notificación personal. Dicha norma contempla la posibilidad de notificar por aviso a la parte que ha sido debidamente citada y quien no comparece para hacer la notificación personal. En otras palabras, la notificación por aviso es una forma de solucionar el evento de aquel individuo que, sabiendo de la existencia de un proceso en su contra, decide no acercarse al juzgado.

Ahora bien, este problema, que en principio es general y abstracto, tiene repercusiones directas en la puesta en marcha del proceso monitorio, pues la pretensión de agilidad se puede esfumar con la actitud pasiva del demandado. Con ello, el papel que juegan los jueces civiles municipales es determinante a efectos de darle impulso al proceso monitorio. Está en cabeza de los jueces civiles municipales darle aplicación a la notificación por aviso en el proceso monitorio, una vez se constate lo contemplado en el numeral 6 del artículo 291 del Código General del Proceso: "Cuando el citado no comparezca dentro de la oportunidad señalada, el interesado procederá a practicar la notificación por aviso" ${ }^{39}$

\section{Conclusiones}

Dada la situación creada, tanto por el Código General del Proceso, como por la Corte Constitucional, se pueden plantear diferentes soluciones procesales: 1 . El juez desacata los mandatos de la Corte Constitucional; 2. El juez declara terminado el proceso por imposibilidad de notificación al demandado; 3 . El demandante retira la demanda y presenta solicitud de conciliación; 4. El demandante retira la demanda y radica solicitud de interrogatorio de parte como prueba extraprocesal; y 5 . El demandante retira la demanda e inicia proceso verbal sumario.

\section{A. El juez desacata los mandatos de la Corte Constitucional}

Esta decisión se justifica en la medida en que el juez solo está sujeto al imperio de la ley. Dicha postura, por demás rechazada desde las visiones más contemporáneas del derecho, requiere un alto nivel de argumentación desde la teoría de los derechos fundamentales. Con ello, el juez no solo debe indicar que tiene plena autonomía, sino que además para el caso en concreto es la mejor solución posible en aras de garantizar el acceso a la justicia.

Dicha postura puede acarrear consecuencias negativas, tanto desde el mensaje que envía el juez al desobedecer una sentencia de constitucionalidad, así como desde la óptica del mismo proceso. El demandado podrá alegar nulidades procesales e intentar acciones constitucionales en contra de la decisión judicial, con lo cual lo que debería ser un procedimiento breve terminaría siendo un proceso más largo y complejo con relación a un proceso verbal.

\section{B. El juez declara terminado el proceso por imposibilidad de notificación al demandado}

Esta posibilidad, que en últimas es la consecuencia directa de la imposibilidad procesal, implica el reconocimiento por parte del Estado de la denegación al acceso de la justicia. El juez reconoce mediante este acto procesal la incapacidad de hacer comparecer a un ciudadano ante la justicia.

\section{El demandante retira la demanda y solicita audiencia de conciliación}

La conciliación es el mecanismo mediante el cual los ciudadanos, ayudados por un tercero, gestionan la 
solución de sus conflictos. Esta posibilidad, viable desde una perspectiva jurídica, es alejada de la realidad. Si no fue capaz un juez de hacer comparecer a un ciudadano ante la justicia, mucho menos lo podrá hacer un conciliador, cuya única herramienta coercitiva es su capacidad de persuadir.

\section{El demandante retira la demanda y radica solicitud de interrogatorio de parte como prueba extraprocesal}

Esta resulta la solución más adecuada académicamente, pues la norma procesal posibilita que, en caso de que el demandado no comparezca al interrogatorio de parte, el demandante incorpore un sobre cerrado, previo a la audiencia, con un cuestionario de preguntas cerradas.

En términos teóricos, dicha sería la situación, sin embargo, desde la realidad, sabemos que si un demandado no hizo comparecencia al juzgado para el proceso monitorio, y ahora se cita para interrogatorio de parte, dicho ciudadano aparece al interrogatorio de parte y no confiesa.

\section{E. El demandante retira la demanda e inicia proceso verbal sumario}

Desde una perspectiva procesal y real, es la mejor opción con que cuenta el demandante. No tiene otra alternativa, pues dicho instrumento procesal sí admite todos los mecanismos de notificación que contiene el Código General del Proceso que no están dispuestos para el proceso monitorio.

Esta última alternativa resultará la solución que todos los abogados litigantes encuentren en la práctica. Lo más adecuado será que, frente a un caso en el cual se cumplan los requisitos de un monitorio, el ciudadano optará por iniciar un proceso verbal sumario y no por un monitorio.

\section{REFERENCIAS}

Amalia Tapias Tapias, Rafael Evelio Muñoz Sánchez y Lili Medina Ortiz. Algunas Vicisitudes del Proceso Monitorio en Colombia-Una Visión Desde la Academia. DIXI 18(24). 2016. Pág. 49-62.

Ángel Landoni Sosa. Luces y Sombras den la Reforma del Código General del Proceso Uruguayo. La Ley 1909 Vigente del 14 de Agosto de 2013. xxxv Congreso Colombiano De Derecho Procesal. (2014).

Antonio Segni. El procedimiento intimatorio en Italia. REVISTA DE DERECHO PRIVAdo 168. 1927. Págs. 307318.

Corte Constitucional de Colombia. Sentencia C-726/2014. (MP Martha Sáchica; septiembre 21 del 2014).

Eduardo J. Couture. Los otros procesos monitorios en el Código General del Proceso Uruguayo. xxxv Congreso Colombiano de Derecho Procesal. (2014).

Felipe Varcalcel Prieto. El Proceso Monitorio. Disponible en http://dspace.sheol.uniovi.es/dspace/bitstream/10651/28743/3/TFMValcarcel\%20Prieto,\%20Felipe. pdf

Gustavo Calvinho. Debido proceso y procedimiento MONitoRio. Disponible en http://www.petruzzosc. com.ar/articulos_y_publicaciones/Debido_Proceso_y_procedimiento_monitorio.pdf

Joan Picó I. Junoy. El Proceso Monitorio una Visión Europea y Española de la Tutela Rápida del CréDITo. Disponible en http://www.icdp.org.co/revista/ articulos/37/JoanPicolJunoy.pdf

José Alejandro Gómez Orozco. Introducción al ProceSo Monitorio Colombiano: Constitucionalidad y Oralidad del Derecho Civil. Librería Jurídica Sánchez R. Ltda. (2014).

Ley $1 / 2000$. De enjuiciamiento civil de enero 7 del 2000 (Enero 8 del 2000). воE 7 (Esp.).

Ley 1564 de 2012. Por medio de la cual se expide el Código General del Proceso y se dictan otras disposiciones. (Julio 12, 2012). Do 48.489.

Ley 15.982/1988. (Octubre 18 de 1988). Do 22.743 (Uruguay).

Ley 19.090/2013. (Junio 14 de 2013). Do 28.743 (Uruguay).

Piero Calamandrei. El Procedimiento Monitorio. Librería El Foro. (2007).

Real Academia Española. Diccionario. Real Academia EsPAÑola. Disponible en http://lema.rae.es/drae/?val=monitorio

Reglamento (CE) N. ${ }^{\circ}$ 1896/2006 [Parlameto Europeo y del Consejo]. Por el que se establece un proceso monitorio europeo. Diciembre 12 del 2006.

Santiago Pereira Campos. Los Proceso Civiles por Audiencias en Uruguay. 20 Años de aplicación exitosa del Código Procesal Civil Modelo para Iberoamérica. Revista Internacional de Estudios sobre Derecho ProceSAL y Arbitraje 2. 2009. 
Ulises Canosa Suárez. Código General del Proceso. Instituto Colombiano de Derecho Procesal. (2012).

Ximena Andrea Lanos Torres y Claudia Patricia Torres Montaño. La Implementación del Proceso Mo- nitorio en el Ordenamiento Procesal Civil CoLOMBIANo. Disponible en http://repository.unimilitar. edu.co/bitstream/10654/10900/1/LanosTorresXimenaAndrea2014.pdf 